MIGRATION

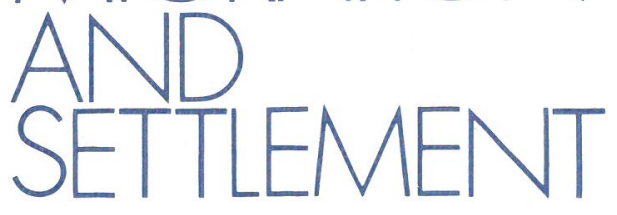

Andrei Rogers

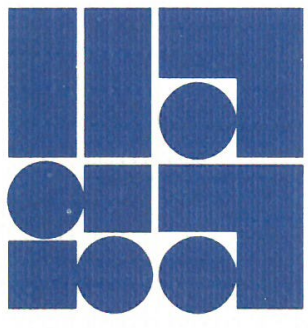

International Institute for Applied Systems Analysis 



\section{MIGRATION AND SETTLEMENT}

Andrei Rogers

International Institute for Applied Systems Analysis

Address delivered to the

IIASA Conference

May, 1976 


\section{INTRODUCTION}

Human settlement issues and problems are becoming the focus of increasing concern among national governments in many West and East European countries, in North America, and in parts of the Third World. Programs to encourage the development of economically declining regions, to stem the growth of large urban centers, and to revitalize the central areas of expanding metropolises are parts of national agendas all over the globe. A notable example is the work of the US Commission on Population Growth and the American Future, which devoted one of its eight research reports entirely to the subject of population distribution policy [1].

Although much of the Commission's attention was directed at national population growth and its consequences, for its research report, Population, Distribution, and Policy, it commissioned papers that directly addressed issues and problems of human settlement and internal migration $[1, \mathrm{pp} . \mathrm{XIV}-\mathrm{XV}]$ :

Major national attention and the Commission's primary focus has been on national population growth. But national growth implies local growth as additional population is distributed in the rural areas, small towns, cities and suburbs across the country. And choices we make about national population growth cannot help but have important meaning for local areas....

Where people move inevitably affects the distribution of the population and the growth of local areas. As 3 result, any national distribution policy will, to some degree, try to intervene in the migration process by encouraging people to move to one place rather than another or not to move at all.

Despite the general recognition that migration processes and settlement patterns are intimately related, one nevertheless finds that the dynamics of their interrelationships are not well understood. An important reason for this lack of understanding is that demographers have in the past accorded migration a status subservient to fertility and mortality, and have almost totally ignored 
the spatial dimension of population growth.* Thus, whereas problems of fertility and mortality long ago stimulated a rich and scholarly literature, studies of migration have only recently begun to flourish. Consequently, one finds today a rather large and growing body of scholarly work on migration awaiting a systematic synthesis $(\mathrm{e} . \mathrm{g} .,[2,3,4])$. The contributions of sociologists in identifying migration differentials (the "who" of migration), of geographers in analyzing directional migration streams (the "where" of migration), and of economists in examining the determinants and consequences of internal migration (the "why" and "so what" of migration) still have not been systematically synthesized into a unified general theory of internal migration.

Out of the recently growing literature on migration, we at IIASA have identified and isolated four related research subtasks that are of particular relevance to our long-term general interests in national settlement systems and strategies (see Figure 1). They are:

- The study of spatial population dynamics;

- The definition and elaboration of a new research area called demometrics and its application to migration analysis and spatial population forecasting;

- The analysis and design of migration and settlement policy;

- A comparative study of national migration and settlement patterns and policies.

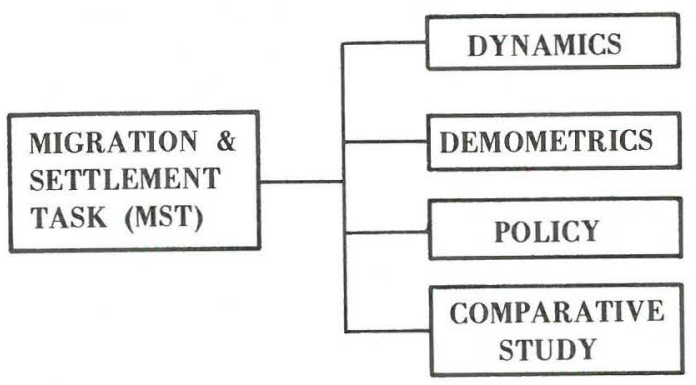

Figure 1. Migration and settlement study.

* There are, of course, a few notable exceptions, e.g., the work of Peter Morrison in the USA and that of Leroy Stone in Canada and of V.I. Perevedentsev in the USSR. 
THE FOUR PRINCIPAL SUBTASKS

Dynamics

The evolution of every spatial human population is governed by the interactions of births, deaths, and migration. Individuals are born into a population, age with the passage of time, reproduce, and ultimately leave the population because of death or outmigration. These events and flows enter into an accounting relationship in which the growth of a regional population is determined by the combined effects of natural increase (births minus deaths) and net migration (inmigrants minus outmigrants). This subtask focuses on such relationships in order to identify and clarify some of the more fundamental spatial population dynamics involved. In addition to its general concern with the expansion of our knowledge of spatial mathematical demography, the dynamics subtask is also focusing on problems of model schedules and populations, sensitivity analysis, spatial zero population growth and aggregation-decomposition procedures (see Figure 2).

SPATIAL MATHEMATICAL DEMOGRAPHY

MODEL SCHEDULES \& POPULATIONS

SENSITIVITY ANALYSIS

SPATIAL ZERO POPULATION GROWTH

AGGREGATION AND DECOMPOSITION

Figure 2. Dynamics.

The age-specific fertility, mortality, and migration schedules of most human multiregional populations exhibit remarkably persistent regularities (see Figure 3 ). The age profiles of these schedules seem to be repeated, with only minor differences, in virtually all developed and developing nations. Consequently, demographers have found it possible to summarize and codify such regularities by means of hypothetical schedules called model schedules.

Model schedules have two important applications: they may be used to infer (or "smooth") empirical schedules of populations, for which the requisite data are lacking (or inaccurate); and they can be applied in analytical mathematical examinations of population dynamics. 

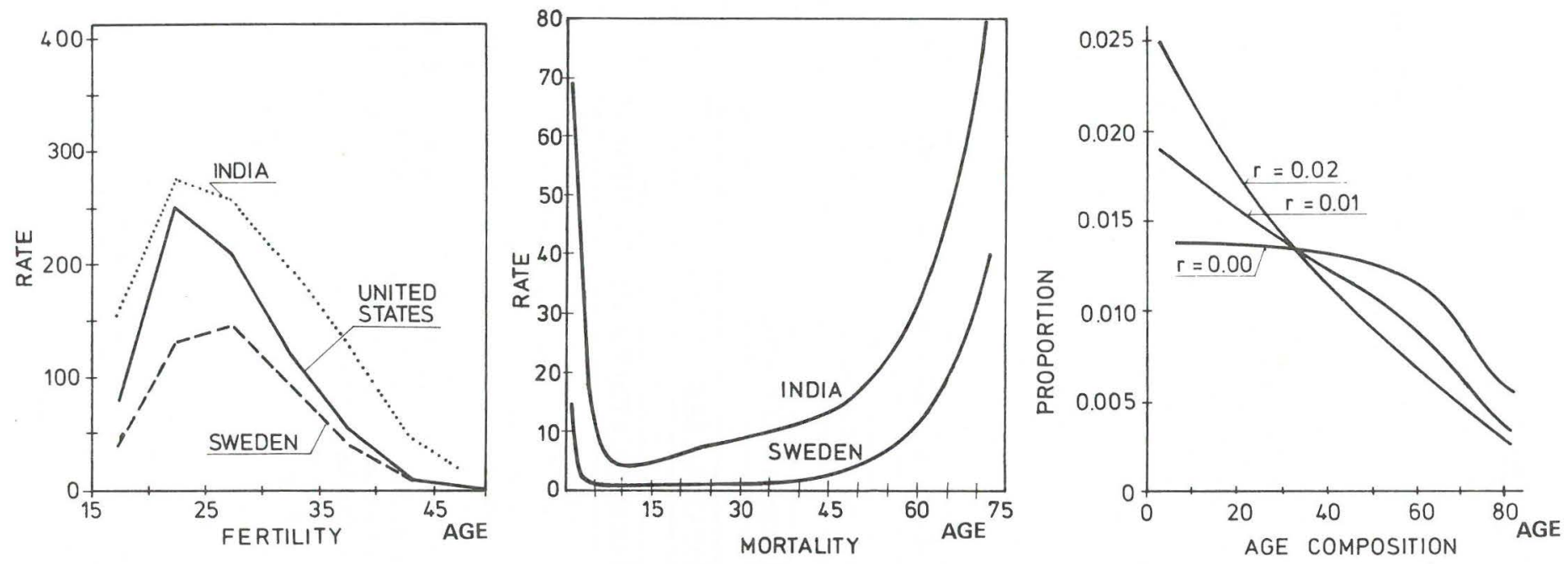

Figure 3A. Non-spatial dynamics.

Sources: $[5,6,7]$ 


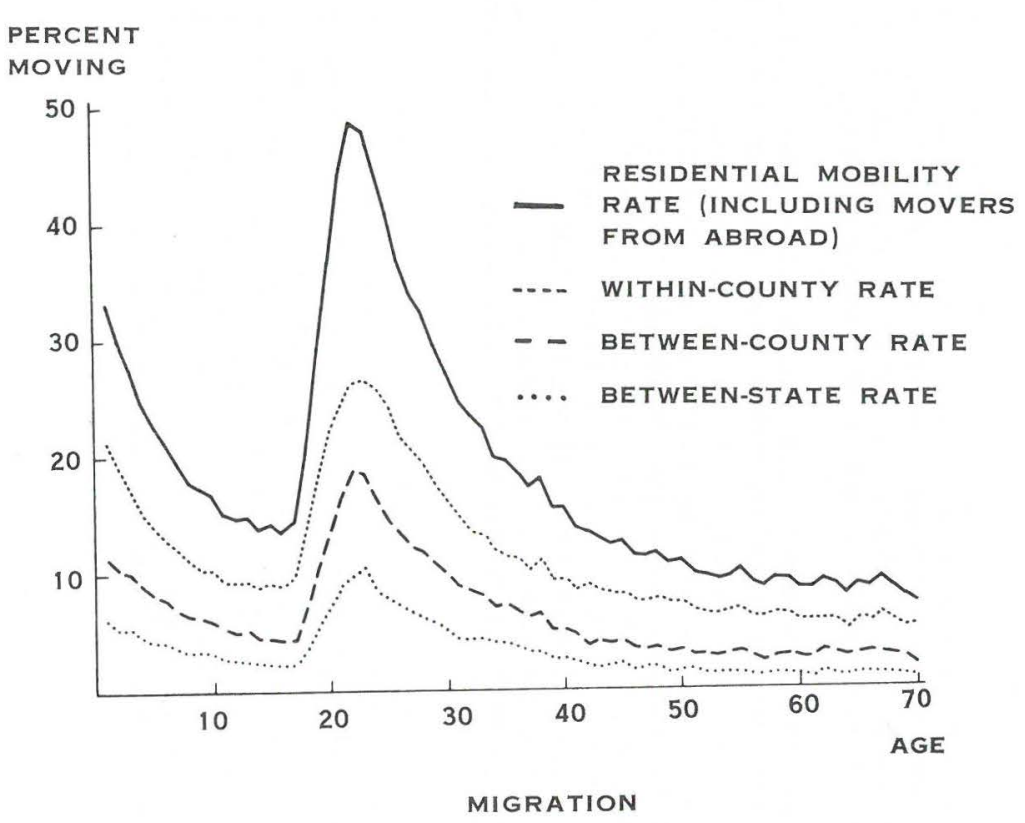

\section{PROPORTION \\ AT EACH AGE}

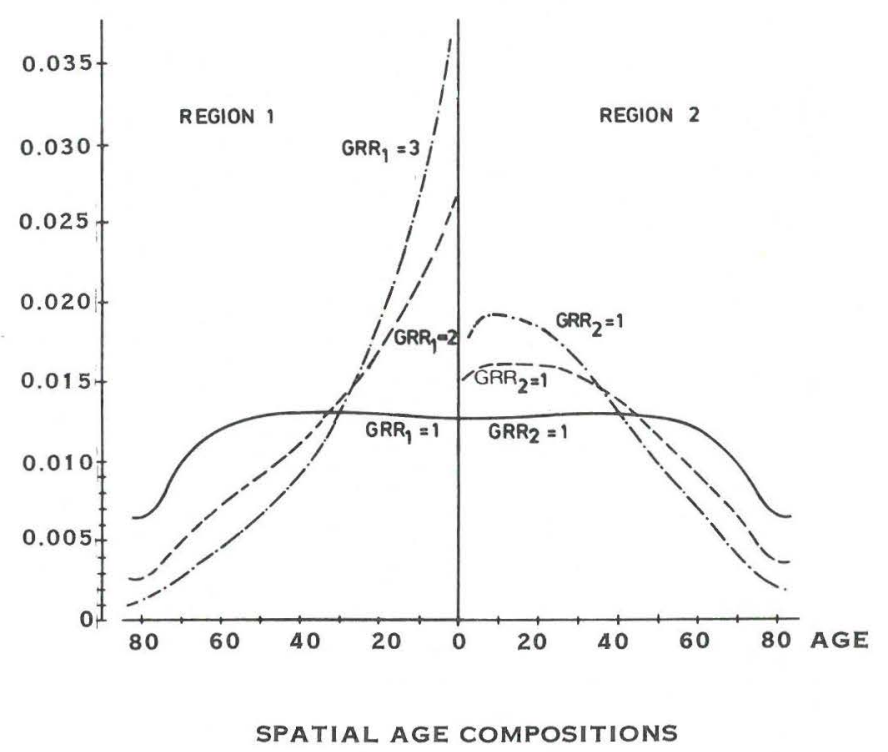

Figure 3B. Spatial dynamics.

Sources: [5,6,7] 
The development of model fertility and model mortality schedules and their use in studies of the evolution of human. populations have received a considerable amount of attention $[8,9,10,11]$. The construction of model migration schedules and their application to studies of the spatial evolution of human populations disaggregated by region of residence, however, have not. We at IIASA are addressing this latter question, and have been able to show how techniques that have been successfully applied to treat the former problem can readily be extended to deal with the latter.

In the realm of spatial mathematical demography, every demographic change may be traced back to a change in age-specific fertility, mortality, and migration rates. But how do changes in these rates affect the dynamics of the spatial demographic system? This question is the subject of our studies in sensitivity analysis. We have derived a set of sensitivity functions that relate a change in spatial demographic statistics to a corresponding change in component rates. The primary purpose of this analysis is to contribute to the knowledge of spatial population dynamics by presenting a unifying technique of impact assessments. In single-region mathematical demography, ordinary differential calculus is used to perform such sensitivity analysis. In multiregional demography, where we deal with matrix and vector functions, the application of ordinary calculus is very complicated, and matrix differentiation techniques must be applied. We have used such mathematical tools to derive analytical expressions that establish the impacts of changing rates on multiregional life table statistics, population projections, and stable population characteristics. These sensitivity functions reveal how each spatial demographic characteristic depends on age-specific rates and how it reacts to changes in those rates.

Increasing concern about the sizes and growth rates of national populations has generated a vast literature dealing with the socio-economic and environmental consequences of a reduction of fertility to replacement levels and the consequent evolution of national populations to a zero-growth condition called stationarity. But where people choose to live in the future presents issues and problems that are potentially as serious as those posed by the number of children they choose to have. The ways in which stabilization of a national population is likely to affect migration and local growth have received very little attention and merit careful study.

We have considered some of the redistributional consequences of an immediate reduction of fertility to bare replacement levels. This analysis has been carried out using the mathematical apparatus developed by demographers to analyze the evolution of national populations to zero growth, with an appropriate extension to include the spatial impact of internal migration. Such an extension shows that stabilization of the regional populations in a multiregional system will alter the relative contributions of natural increase and migration to regional growth. Regional age 
compositions will also be affected, and in ways that are strongly influenced by the age patterns of migration. Retirement havens, for example, will receive proportionately higher flows of inmigrants as a national population increases in average age, whereas destinations that previously attracted mostly younger migrants will receive proportionately fewer inmigrants. Finally, the redistributional effects of stabilization will depend in a very direct way on the redistributional pattern of total births that is occasioned by fertility reduction.

During the past two decades social scientists have come to model dynamic socio-economic systems of growing size and complexity. Despite a heavy reliance on ever more sophisticated highspeed digital computers, their capacity for handling s'ich systems has not kept pace with the growing demands for more detailed information. Consequently, it is becoming especially important to identify those aspects of a system that permit one to deal with parts of it independently from the rest or to treat relationships among particular subsystems as though they were independent of the relationships within those subsystems. These questions are, respectively, those of decomposition and aggregation, and their application toward "shrinking" large-scale population projection models is one element of our spatial population dynamics subtask.

\section{Demometrics}

In 1938, the US National Resources Committee published a major demographic study which, after adopting a set of "reasonable" assumptions with regard to future fertility, mortality and net immigration, projected the total us population in 1980 to be 158 million, at which time it was also to have reached a state of equilibrium. The US population passed the 158 million mark less than fifteen years later and today exceeds 210 million.

It is difficult to fault such projections, for it is very unlikely that any competent demographer, faced with the same situation, would have come up with a radically different set of projections. How then, can the accuracy of such exercises in social prediction be improved? We at IIASA believe that the development of a discipline called demometrics is a necessary first step (see Figure 4).

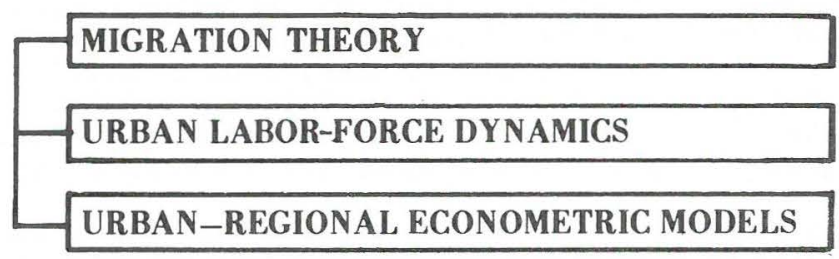

Figure 4. Demometrics. 
In the field of economics a division is generally made between the areas of mathematical economics and econometrics. The former deals principally with abstract mathematical descriptions of economic dynamics and economic growth; the latter treats statistically-estimated relationships between basic economic variables. Analogous distinctions are made to distinguish mathe matical psychology from psychometrics, mathematical biology from biometrics, and mathematical sociology from sociometrics. In a similar vein, we at IIASA are distinguishing mathematical demography from demometrics, the development and elaboration of which forms the major focus of the second of the four principal subtasks in the migration and settlement study.

In a broad sense, demometrics is concerned with the unified application of mathematical and statistical methods to the study of demographic phenomena. The principal aim of this discipline is to establish empirically quantitative relationships between demographic and socio-economic variables. It is important not to confuse this activity with mathematical demography and statistical techniques (as does winkler [12]), or with demographic statistics (as does the layman). Demometrics is distinguished by its fusion of the deductive approach of mathematics, the inductive approach of statistics, and the causal approach of demographic theory.

The 1938 projection by the US National Resource Committee, like most projections today, did not link demographic variables with economic variables. Until very recently, this has been a standard practice in both disciplines. That is, demographers typically have given economic variables only cursory treatment in their models, and economists have accorded demographic variables a similar status. In the words of Hoover [13, p.73]:

Purely demographic and purely economic models... are multitudinous and often highly complex. This makes even more striking the relatively primitive state of the art that prevails in the linking of demographic and economic variables.

Much of our work in the demometrics subtask is directed toward advancing the state of the art in this fledgling activity Our fundamental approach has been to couple an economic model with a demographic model by means of linkages through the consumption and labor sectors (see Figure 5). The former linkage appears in the form of a consumption function that demands the economy to produce a certain output for the population to consume The latter linkage takes the form of a migration labor-force equilibrating model that views the demographic model as the supplier of labor and the economic model as the demander of labor The two models operate recursively in developing forecasts of demographic and economic growth that are internally consistent.

The consistent-forecasting framework just outlined has led us to consider in some detail two related areas of research: migration theory, and urban labor-force dynamics. 


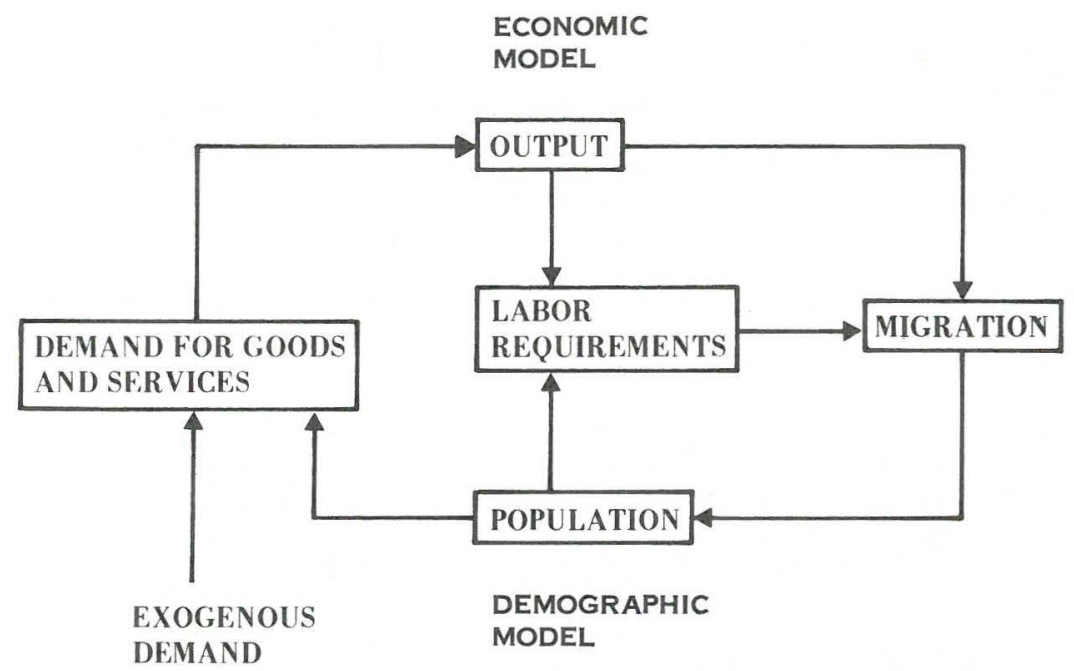

Figure 5. Consistent demographic-economic forecasting.

Theory- and model-building in the field of migration research has both a micro- and a macro-dimension. The former is dominated by the economist's perspective of migration as an investment in human capital-a perspective which holds that "migration may be viewed as a comparison of the present value of the benefits and costs of moving" [14, p.365]. The macrotheory of migration, on the other hand, focuses on aggregate movements and, like macro-economics, generally fails to relate in any precise manner its theories with those concerning individual decision-making (i.e., the microtheory).

Although an economic model forecasts the quantity of labor that will be demanded, it is important to know how much of that labor will be supplied by the resident population and how much by new migrants. Inmigration, for example, implies a larger population, whereas a change in the labor-force participation rate of residents does not. Both sources of labor supply compete for the same jobs, and each introduces a different influence on the ultimate forecast.

A large literature on urban labor-force dynamics is available. In the past, much of it has been concerned with proving or disproving the "added worker" and "discouraged worker" hypotheses [15]. Recently, attention has been directed at the dynamics of the job search process itself [16]. We believe that this body of literature will ultimately provide the connecting link between urban migration and labor-force dynamics; consequently, an increasing amount of our research effort is being directed toward establishing such a connection. 
Policy

The policy analysis and design subtask of the migration and settlement study is surveying the fundamental dimensions of current national migration and settlement policies. In particular, it is examining the consequences of migration, those affecting b the origin region and the destination region. And it is evaluat the utility of the "optimal policy" paradigm of Tinbergen that $r$ cently has been usefully applied by mathematical economic planne (see Figure 6).

\section{INDIVIDUAL CONSEQUENCES OF MIGRATION}

SOCIETAL CONSEQUENCES OF MIGRATION

OPTIMAL POLICY MODELS

Figure 6. Policy.

A wide variety of countries are striving to channel urban growth to certain regions and to divert it from others. Generally, such national urbanization or human settlement policies have been defended on the grounds of either national efficiency or regional equity. The arguments often are framed in terms of an underlying conceptual framework known as "growth-pole theory" (e.g., [17]). Migration is an important element of this theory [17, pp.149-150]:

One justification for pursuing a growth-centre policy in a depressed region relates to the supposed ability of major urban centres to generate and to attract migrants. There are three arguments here.... These three arguments relate successively, then, to the generation, interception and attraction of migrants. And so we must look in this chapter not at the effects of migration on the fortunes of the growth centre or its hinterland...but at the causes and nature of migration.

We at IIASA are focusing on the causes of migration in the demometrics subtask and on the consequences of migration (i.e., its consequence for the individual migrant) in the policy analysis subtask.

Several scholars of internal migration have concluded that the experience of migration affects favorably the personal wellbeing and satisfaction of the migrant (e.g., $[18,19])$. However, the societal consequences of migration often fall unequally on different groups. 
Migration, as a mechanism for transferring labor from labor surplus areas to labor deficit areas, moves the national economy toward greater efficiency. But this adjustment of the national labor market has local consequences with regard to equity. And it is these negative consequences that often fall on those "left behind", since it is the most productive members of the labor force that are the ones who move away, leaving behind localities increasingly unattractive for industrial investment [19] .

The various individual and societal consequences of internal migration have broad implications for national policies dealing with migration and settlement. The built-in conflict between the goals of national efficiency and regional equity is a fundamental "fact of life" in the design of such policies, one that ultimately can be resolved only in the political arena. A potentially useful tool for illuminating some of the tradeoffs is offered by the formal theory of economic policy, first proposed in 1963 by $J$. Tinbergen [20] in the field of economic planning (see Figure 7 , and [21, pp.11-12]):

The theory of economic policy is concerned with the analysis of decision situations and policy problems, using that part of general economic theory which can be quantitatively applied to economic data in some operational sense... This analytical framework has been used implicitly in other contexts which are not economic in any conventional sense. For instance,

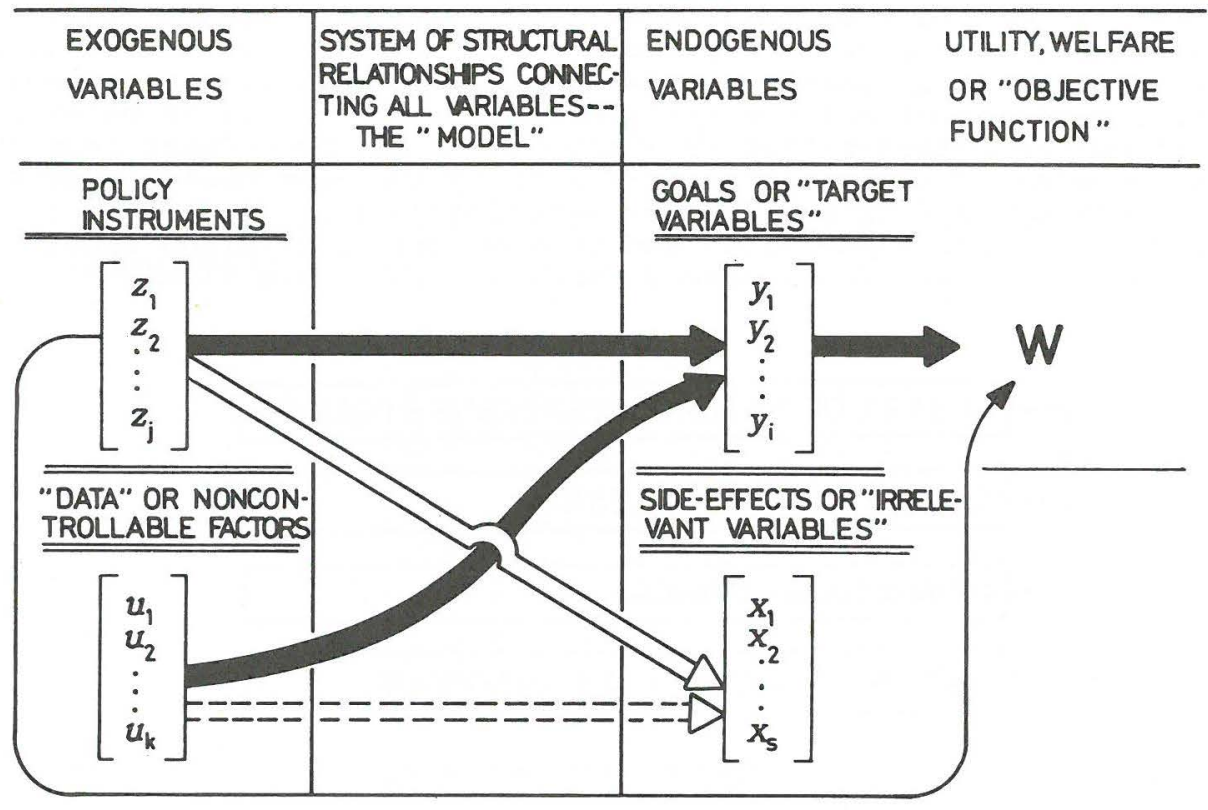

Figure 7. The Tinbergen policy framework.

Source: [21] 
control engineers and communications systems analysts, in developing the theory of servomechanisms and the principles of automatic control of a complex physical system, start by describing the "laws of motion" of the existing physical system by a set of differential or difference equations involving variables which are controlled (inputs) and other variables which are the effects or outputs. Comparisons are made between alternative outcomes over time when the controlled variables are completely absent from the system and when they are present at different assigned levels. A set of optimal controls is then chosen which in some sense provides the best possible outcome, e.g., which optimizes a given performance integral in a feedback control in the servomechanism theory.

As the authors of the above quotation point out, "the logical structures of some problems of economic policy are formally analogous to problems of decision-making and stabilization or 'steering' in other fields". We believe that spatial demography is one such field, and we therefore are actively exploring the utility of this approach for migration and settlement policy analysis and design.

\section{Comparative Study}

The comparative study of migration and settlement (Figure 8) has adopted the general framework of two recently published studies carried out in a closely related area. Specifically, the comparative analysis of human migration and redistribution is being carried out in a manner that is analogous to the procedures used by two studies of human mortality-fertility and reproduction, namely, the book by Keyfitz and Flieger entitled Population: Facts and Methods of Demography [22], and that edited by Berelson entitled Population Policy in Developed Countries [23] (see Figure 9).

SURVEY OF NATIONAL PATTERNS \& POLICIES

CASE STUDY: USA - USSR

OTHER CASE STUDIES

DATA BANK \& COMPUTER HANDBOOK

Figure 8. Comparative study. 


\section{POPULATION}

Facts and Methods of DEMOGRAPHY

Nathan KEYFIT2

University of California Berkeley

Wilhelm FLIEGER SVD

University of San Carlos Cebu City, Philippines

W. H. FREEMAN and COMPANY San Francisco

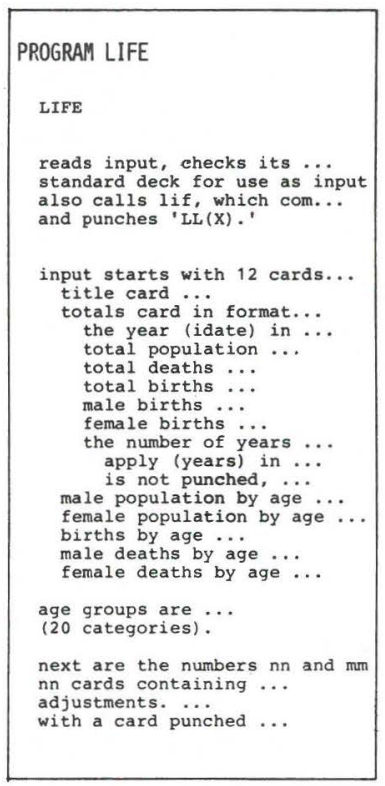

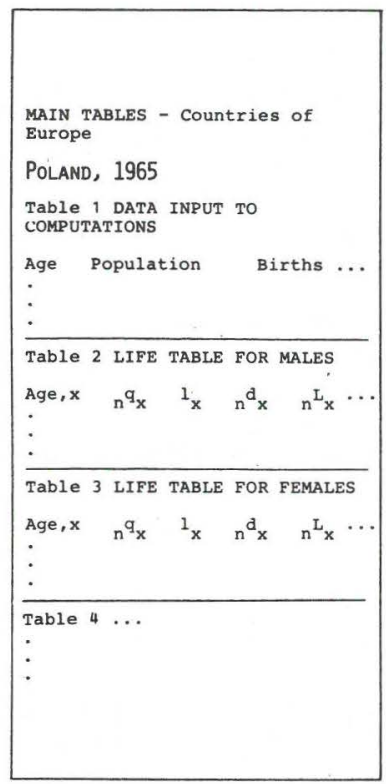

Figure 9A. The Keyfitz-Flieger Book [22].

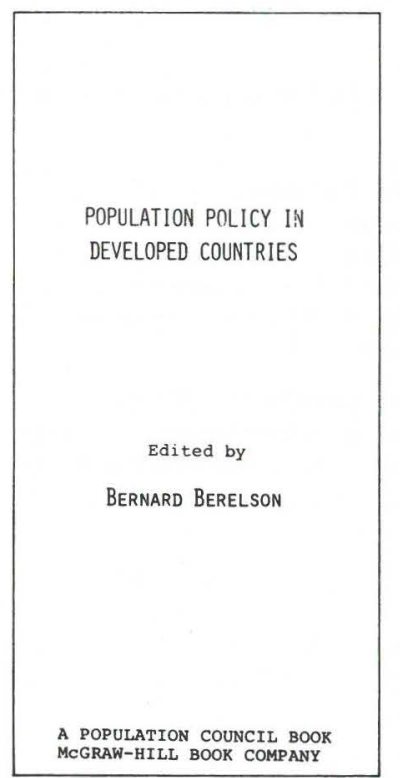

The Authors

Bernard Berelson. President of the Population Council,

IRELAND

Brendan M. Walsh

ISRAEL

Dov Friedlander

FINLAND

Paavo Piepponen

SWEDEN

Lena Jonsson

BULGARIA

Ivan Stefanov

-

JAPAN

Minoru Muramateu

Toshio Kuroda

UNITED STATES

Charles F. Westoff

SOVIET UNION

Dmitri I. Valentei

Figure 9B. The Berelson Book [23] . 
The Keyfitz and Flieger book focuses on observed age- and se specific mortality and fertility schedules, and projects the evolution of the populations exposed to these schedules. In order $t$ examine the population trends of the present day, the authors col lect together a data bank of population statistics from more than 90 countries and subject these to a standardized analytical process.

If national population growth is the primary focus of the Keyfitz and Flieger study, its principal approach for examining such growth is embodied in a collection of computer programs that provide the vehicle for analyzing population growth in a consistent and uniform manner. These programs and the mathematical models that underlie them are also presented in the study volume.

Finally, the major contribution of the Keyfitz and Flieger study is the uniform application of a consistent methodology to a vast amount of data in order to trace population growth trends in a large number of countries.

The focus, approach, and contribution of the Keyfitz and Flieger study have much in common with those of the comparative study of migration and settlement. The focus of the latter also is population growth, but spatial population growth. The approac also relies on a uniform set of computer programs, but these embody the models of multiregional mathematical demography [24]. And the expected contribution also is that of linking data and theory, but the data and theory that are linked are spatial in character.

There are several important differences between the two stud formats :

- A primary concern of the Keyfitz and Flieger study is population reproduction and the demographic transition from high to low birth and death rates. An important focus of the comparative migration and settlement study is population redistribution and the mobility transition [25] from low to high migration rates.

- The Keyfitz and Flieger study is the product of two authors; the comparative migration and settlement study requires the collaborative efforts of an international team of scholars residing in various member and nonmember nations.

- The Keyfitz and Flieger study identifies trends and the numerical consequences of the continuation of such trends into the future; the comparative migration and settlement study is, in addition, striving to link national trends with explanatory variables.

- Although Chapter 4 of their book is entitled "Policy Dilemmas and the Future", the Keyfitz and Flieger study does not deal with national policies. (Their Chapter 4 is only three pages long.) The comparative migration 
and settlement study, however, explicitly considers the national migration and settlement policies of each country represented. In this respect, the study resembles more the study of population policies coordinated by Berelson [23].

The book edited by Berelson is a review of population policies in 24 developed countries. The individual chapters were written by collaborating scholars residing in the particular countries. Thus, for example, Professor Charles Westoff of Princeton's Office of Population Research wrote the chapter on population policy in the USA, and Professor Dimitri Valentei of Moscow State University's Population Center authored the chapter on population policy in the USSR.

According to Berelson, "the collaborators were given a common outline as a guide to the topics to be addressed, but each author was free to prepare his report in his own manner". It is therefore not surprising that different authors elected to emphasize different aspects of population policy, and drew on different kinds of demographic data to develop their presentations. Thus the book is somewhat uneven in its coverage and in the data and indicators put forward by the various authors.

In the migration and settlement study we are striving to marry the Berelson approach with the Keyfitz-Flieger approach in order to capture the best features of each. Every national analysis in the comparative study of migration and settlement is, as in the Berelson study, being carried out in collaboration with scholars residing in the countries being studied. However, most of the data, projections, and indicators that form the foundation of the analysis are being processed, as in the Keyfitz-Flieger study, by a common set of computer programs. These data and programs will be published.

\section{AN ELEMENT OF THE FIRST SUBTASK: SPATIAL ZERO POPULATION GROWTH}

\section{World Zero Population Growth}

Most demographers would agree that current rates of world population growth cannot continue for more than a century or two without producing a collapse of the present world system. A much publicized example of the recent wave of concern over the world's "population explosion" is the study sponsored by the club of Rome entitled The Limits to Growth, in which it is asserted that [26, p.23]:

If the present growth trends in world population, industrialization, pollution, food production, and resource depletion continue unchanged, the limits to growth on this planet will be reached sometime within the next one hundred years. The most probable result will be a rather sudden and uncontrollable decline in both population and industrial capacity. 
A notable effort to examine a range of alternative projectio of world population growth is the recent book by Frejka entitled The Future of Population Growth: Alternative Paths to Equilibriu [27]. In this book, the author presents several projections of the populations of the developed and less developed regions of th world and its major areas. All the projections ultimately converge to a stationary "zero growth" population and differ only in the paths by which this zero growth is achieved. Five major path (or projections) are offered. These differ, one from another, by the length of the period of fertility decline to replacement leve $(0,10,20,50$, or 70 years $)$.

According to Frejka, the population of the world in 1970 was approximately 3.6 billion, out of which a total of 1.1 billion were living in the more developed countries and 2.5 billion resided in the less developed nations. The age compositions of these two populations were significantly different: the median age of the former was 31 years whereas that of the latter was 19 years. The most important implication of this difference is simply that the younger population has a proportionately much larger stock of future childbearers and, in consequence, a much larger built-in "momentum" for growth.

Figures 10 and 11 summarize Frejka's principal findings. Figure 10 contrasts the five major growth projections, demonstrating that [27, pp.52-54]:

Provided the average fertility conditions changed so substantially that the NRR [net reproduction rate] declined from its estimated current (1965-70) level of 1.9 to a level of 1.0 within a few years, the present world population of 3.6 billion would... settle at around 5.6 to 5.7 billion inhabitants. If, however, a world fertility decline were brought about very gradually so that in, say, 70 years an NRR of 1.0 were attained, then... world population would settle at over 15 billion.

Figure 11 disaggregates the population projection of Figure 10 by "more developed" and "less developed" regions of residence. The difference between the two sets of trajectories is striking evidence that "future world population growth will increasingly be determined by the nature of population growth in the less developed regions" [27, p.73].

Frejka's book is part of a vast literature on the social, economic, and environmental impacts of a reduction of fertility to replacement level and the consequent evolution of populations to a zero growth condition. But where people choose to live in the future presents issues and problems that are potentially as serious as those posed by the number of children they choose to have. Yet the spatial implications of reduced fertility have received relatively little attention, and consequently, we are ill-equipped to develop adequate responses to questions such as the one recently posed by the US Commission on Population 
Growth and the American Future* [28, p.13]:

How would stabilization of the national population affect migration and local growth?

Recognizing the importance of examining the spatial consequences of zero population growth, we at IIASA have applied our models of spatial population dynamics to the study of spatial zero population growth.

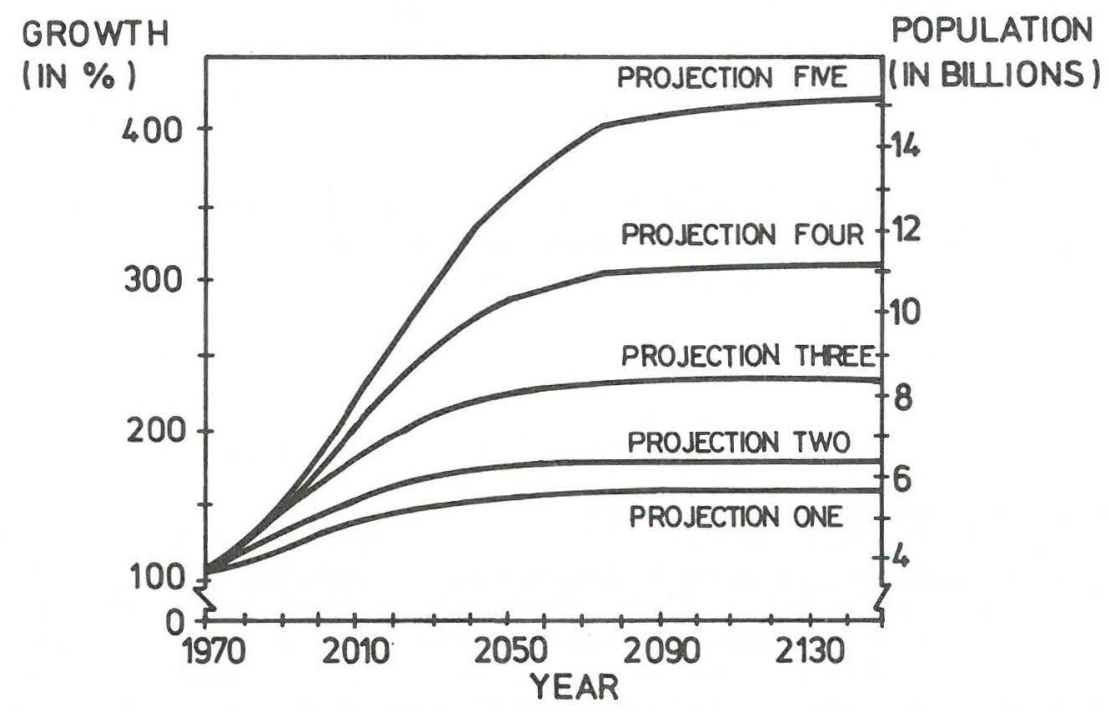

Figure 10. Growth of world population, projections one to five standard set, 1970-2150 (in absolute numbers and in percentages).

Source: [27]

* A notable exception is the work of Peter Morrison, who concludes: "...demographic processes interact in subtle and often complex ways, and the mechanisms by which declining fertility would influence population redistribution are only partially understood. Their elucidation can furnish a clearer picture of how and under what circumstances population redistribution can be influenced by public policy" [29, p.547]. 

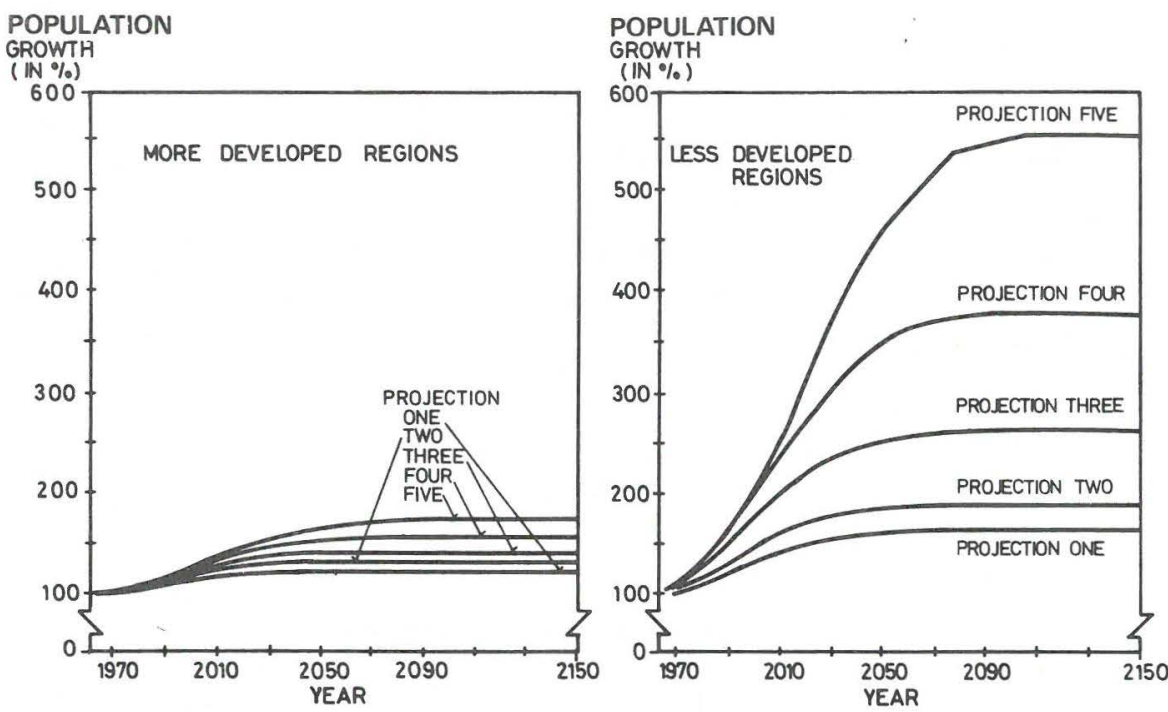

Figure 11. Growth of population of more developed and less developed regions, projections one to five, standard set, $1970-2150(1970=100)$.

Source: [27]

\section{Spatial Zero Population Growth}

Zero population growth for a nation implies an average of zero growth for local areas. This, of course, still allows for the possibility of nonzero growth in particular localities. Thus spatial zero growth, like temporal zero growth, may be viewed either as a condition that ultimately prevails uniformly, or one that exists only because of a fortuitous balancing of regional rates of positive growth, of zero growth, and of decline. Since no obvious advantages arise from the latter case, demographers quite naturally have viewed the attainment of temporal zero growth in the long run in terms of an indefinite continuation of temporal zero growth in the short run. We follow this tradition and view the attainment of spatial zero growth in the long run in terms of temporal zero growth within each region of a closed multiregional population system. In consequence, we confine our attention here to the evolution of a particular subset of stationary populations, called spatial zero-growth populations, i.e. stable multiregional populations that have a zero growth rate. Thus we augment the usual twin assumptions of a fixed mortality schedule and a fixed fertility schedule, set at replacement level with the assumption of a fixed migration schedule. 
If age-specific death rates are fixed and replacement level birth rates remain unchanged, a population that is closed to migration will ultimately evolve into a stationary population. The characteristics of such a population are well known. The number of individuals at any age would remain fixed, and the total number of deaths would equal exactly the total number of births. Because mortality risks would be relatively low from just after birth through middle age, the age composition of such a population would be nearly rectangular until ages 50 or 60 , tapering much more rapidly thereafter with the increase in death rates among the older population.

The maintenance of a stationary population requires that parents have only as many children as are needed to maintain a fixed number of births every year. This means, for example, that a 1,000 women must on the average produce a 1,000 baby girls during their lifetime. Moreover, since some girls will not survive to become mothers, those who do must have slightly more than 1,000 daughters in order to compensate for those who don't. Hence the gross reproduction rate (GRR) must be greater than unity by an amount just sufficient to maintain a net reproduction rate (NRR) of unity. For example, about 97 to 98 percent of the women in the United States today survive to the principal ages of childbearing. Consequently, those who do must have approximately 1.027 daughters, on the average, as they pass through the childbearing ages. In other words, the GRR must be 1.027 in order for the NRR to be unity.*

\section{The Momentum of Spatial Zero Population Growth}

Differences between most observed population age compositions and those of stationary populations make it virtually impossible to attain zero growth in the near future. A closed population's birth rate and growth rate depend on its fertility schedule and its age composition. Consequently, whether and how long a population continues to grow after achieving a net reproduction rate of unity depends on that population's age composition and its degree of divergence from that of a stationary population. The ratio by which the ultimate stationary population exceeds a current population is the "momentum" of that population, a quantity that recently has been given analytical content by keyfitz [30] who shows that the momentum of a population numbering $\mathrm{K}$

* Because there are usually about 105 baby boys born for every 100 baby girls, mothers in a stationary population of males and females would need to have a total rate of reproduction about three percent more than twice 1.027 . In this way we obtain the total fertility rate of 2.11 used, for example, in the US Census Bureau projections [31]. 
individuals, with an age composition close to stable, may be approximated by the expression

$$
\frac{\hat{Y}}{\mathrm{~K}}=\frac{\mathrm{be}(0)}{r \mu}\left(\frac{\mathrm{R}(0)-1}{\mathrm{R}(0)}\right),
$$

where $b$ is the birth rate, $r$ is the rate of growth, e(0) is the expectation of life, and $\mathrm{R}(0)$ is the net reproduction rate--all measured before the drop in fertility--and $\mu$ is the mean age of childbearing afterward. Observe that equation (1) also may be expressed as

$$
\hat{Y}=e(0) \hat{Q},
$$

where

$$
\hat{Q}=\frac{b K}{r \mu}\left(\frac{R(0)-1}{R(0)}\right)
$$

is the number of births in the (ultimately) stationary population. Note that since the derivation assumes the population to be approximately stable before the decline in fertility, b and $r$ are intrinsic stable rates of the initial (nonstationary) regime of growth.

Straightforward population projection calculations may be used to obtain the future population that evolves from any particular observed or hypothetical regime of growth. Therefore equation (1) is not needed to obtain a numerical estimate of an ultimate stationary population. However, Keyfitz's simple momentum formula gives us an understanding of the population dynamics that are hidden in the arithmetical computations of a population projection. It identifies in an unambiguous way the five parameters of a current population that determine the size of the ultimate stationary population.

We at IIASA have developed a spatial generalization of Keyfitz's momentum formula. We begin by estimating the ultimate size of the total stationary births, $\hat{Q}$, by means of equation (1); next, we distribute that total among the various regions according to the allocation defined by the characteristic vector associated with the unit root of the "reduced" net reproduction matrix $\hat{R}(0)$; then premultiplying the resulting vector by the matrix orf expectations of life at birth $e_{\sim}(0)$, we find the vector of regional zero-growth populations $\{\underset{\sim}{\hat{\gamma}}\}, \sim i . e .$,

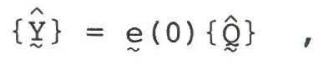


where $\{\hat{Q}\}$ is scaled to sum to $\hat{Q}$, the latter coming from Keyfitz's single-region formula.

Equation (2) may be used to dramatically underscore our earlier assertion that where people choose to live in the future presents issues and problems that are potentially as serious as those posed by the number of children they choose to have. Consider, for example, the projection to zero growth of India's population that was recently carried out by Ryder on the basis of the following assumptions [32, p.6]:

To simplify the task of projecting the population of India, we make the following assumptions: it is a stable population with a growth rate $r=+0.025$ and survival functions corresponding to those labelled "West, level 13" (for which the female and male expectations of life at birth are 50 and 47.114 , respectively) in the Coale/Demeny collection; the mean age of (gross) maternity $\mathrm{m}=29$; the ratio of male to female births $\mathrm{k}=1.05$; and the current population size is 600 million.

From these assumptions it follows that the initial number of female births per annum $B(t)$ equals 12.156 million, $R(0)$ equals 2.019 , and $\mu$ equals 28.672 years. Applying equation (1), Ryder finds a $\hat{Q}$ of 8.558 million and a zero growth population of 851 million. He then shows that if India's survival level rises to $e(0)$ equals 70 years for females and $e(0)$ equals 66.023 years for males, and

...if replacement level fertility takes 40 years to achieve and the mean age of gross reproduction declines from 29 to 27 , the ultimate female birth cohort size will be...15.029 million. Given that value,...the consequent ultimate population size is 2.094 billion [32, p.7].

Ryder concludes that "the thought of a population of 2.1 billion for India is staggering", and goes on to examine in what respects the components of his projection may be modifiable.

There is no question but that a 2.1 billion population for India is staggering. What is even more mind-boggling, however, is that approximately 70 to 80 percent of this total is likely to be found in that nation's already teeming and over congested urban areas (the current figure is 20 percent). To show this, we need only introduce a few additional assumptions and then apply equation (2). Specifically, assume that life expectancy is 55 years in urban areas and 45 in rural areas, with the migration pattern being such that

$$
\underset{\sim}{e}(0)=\left[\begin{array}{ll}
u^{e} u(0) & r^{e} u^{(0)} \\
u^{e}{ }_{r}(0) & r^{e} e_{r}(0)
\end{array}\right]=\left[\begin{array}{rr}
50 & 20 \\
5 & 25
\end{array}\right] .
$$


Assume, further, that the spatial pattern of net reproduction after the drop to replacement fertility is given by

$$
\hat{\sim}(0)=\left[\begin{array}{ll}
0.85 & 0.45 \\
0.15 & 0.55
\end{array}\right] \text {. }
$$

Then,

$$
\{\hat{Q}\}=\hat{Q}\left[\begin{array}{l}
3 / 4 \\
1 / 4
\end{array}\right]
$$

and

$$
\{\underset{\sim}{\hat{Y}}\}=\left[\begin{array}{l}
\hat{Y}_{u} \\
\hat{Y}_{r}
\end{array}\right]=\hat{Q}\left[\begin{array}{rr}
50 & 20 \\
5 & 25
\end{array}\right] \times\left[\begin{array}{l}
0.75 \\
0.25
\end{array}\right]=\hat{Y}\left[\begin{array}{l}
0.80 \\
0.20
\end{array}\right] \text { million }
$$

Thus, under our assumptions, a fertility reduction that allows a woman one baby girl puts roughly 80 percent of India's ultimate zero-growth population into urban areas (Alternative $\mathrm{A}$ in Figure 12). A similar calculation using an alternative scheme of fertility reduction (i.e., proportional fertility reduction) give about 72 percent for the same figure (Alternative B in Figure 12)

Figure 12 summarizes the above results. Note that the "momentum" for urban areas varies from 500 to 1400 percent, depending on the time that it takes for the fertility decline to occur and on the spatial pattern of that fertility reduction.

\section{CONCLUSION}

Internal migration and human settlement patterns are increasingly becoming subjects of governmental concern, both in developed countries and in the developing nations of the Third World. Whether the problem is that of ensuring an adequate supply of labor in Siberia or one of stemming the vast flood of migrants from the farms and villages of Latin America to its overcrowded major cities, the need for a well-developed understanding of the relationships between spatial population dynamics and socio-economic development is clear. A stark reminder of this need recently appeared on the editoral page of the International Herald Tribune [in 33, p.4]:

Bombay - The doors of the jumbo jet swing open and the night air rushes in. The warm stench of industrial waste and human excrement overpowers the smell 

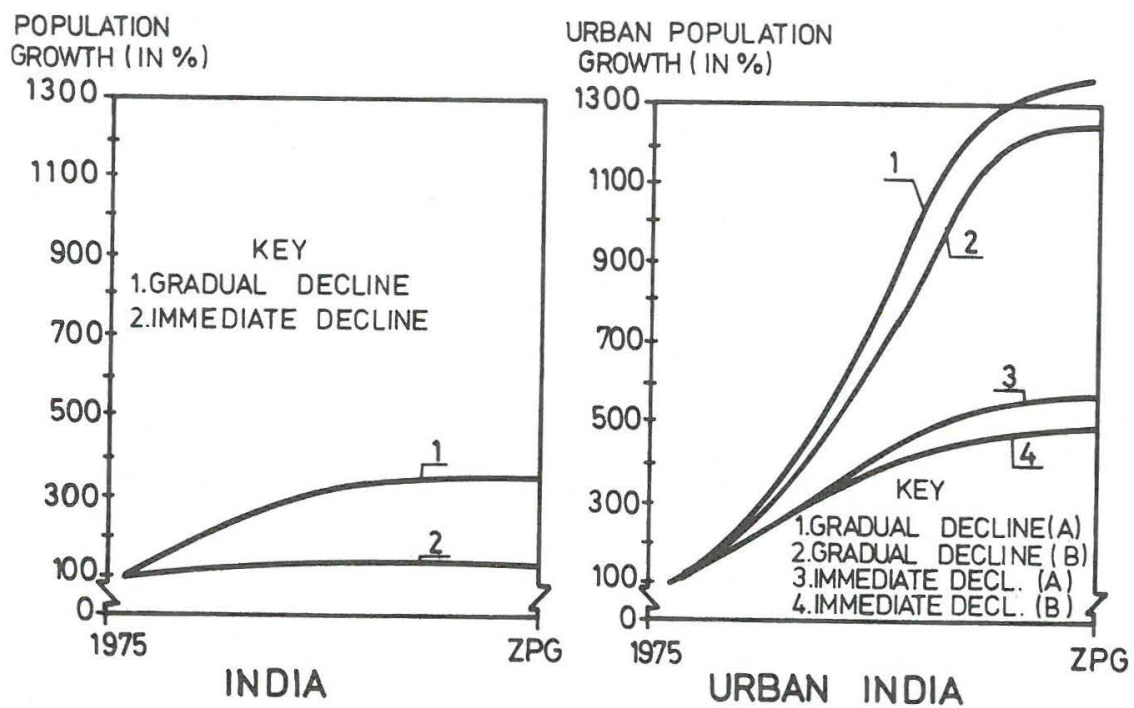

Figure 12. Growth of India's population to zero population growth (ZPG).

Source: [34]

of jet exhaust. This is Bombay--city of six million, industrial giant, metropolis of the western seaboard, ringed by forests of chemical plants, textile mills and engineering factories. Inside are the people, crushed together, man on man, woman on woman, child on child. Squeezed between humanity run the open sewers, full of the putrid outpourings of an overwrought civilization.

Bombay at the end of the 17 th century had only 10,000 inhabitants. By 1872 it was 644,000 . Today, the density of population is higher than Manhattan's and growing steadily. Only economic recession keeps the numbers down. For once the wheels of industrial society move, the people come in their hordes leaving the economic insecurity of the villages for this city where they think there must be hope.

Dr. A. Mehta, chief economic adviser of Tata Industries...estimates the number of under-employed as about 20 million, or 10 percent of the labor force. $B y A D 2000$, he argues, India will have to find jobs for an additional 200 million people.... He concludes that the urban-industrial world is not the answer to this problem...[He] believes this great nation... will have to turn its back on its old developmental ideas ...of escaping poverty through industrialization. It will have to begin taking its agriculture seriously and hold its people on the land and in the villages. 


\section{$\underline{\text { References }}$}

[1] US Commission on Population Growth and the American Futu Population, Distribution, and Policy, S.M. Mazie, e Vol. 5 of Commission research reports, US Governmen Printing Office, Washington, D.C., 1972.

[2] Greenwood, M.H., Research on Internal Migration in the United States: A Survey, Journal of Economic Liter ture, 13 (1975), 397-433.

[3] Price, D.O. and M.M. Sikes, Rural-Urban Migration Resear in the United States: Annotated Bibliography and Synthesis, US Government Printing Office, Washingto D.C., 1975 .

[4] Shaw, R.P., Migration Theory and Fact: A Review and Bib ography of Current Literature, Regional Science Research Institute, Philadelphia, Pa., 1975.

[5] Bogue, D.H., Principles of Demography, Wiley, New York, 1969 .

[6] Long, L.H., New Estimates of Migration Expectancy in the United States, Journal of the American Statistical Association, 68 (1973), 37-43.

[7] Rogers, A. and F. Willekens, Spatial Population Dynamics RR-75-24, International Institute of Applied System Analysis, Laxenburg, Austria, 1975.

[8] Coale, A.J. and P. Demeny, Methods of Estimating Basic Demographic Measures from Incomplete Data, United Nations, New York, 1967.

[9] Coale, A.J. and P. Demeny, Regional Model Life Tables and Stable Populations, Princeton University Press, Princeton, N.J., 1966.

[10] Coale, A.J., The Growth and Structure of Human Populatic Princeton University Press, Princeton, N.J., 1972.

[11] Rele, J.R., Fertility Analysis Through Extension of Stak Population Concepts, Institute of International Stl ies, University of California, Berkeley, Calif., 1s

[12] Winkler, W., Demometrie, Duncker and Humbolt, Berlin, 1!

[13] Hoover, E., Basic Approaches to the Study of Demographic Aspects of Economic Development: Economic-Demogra] Models, Population Index, 37 (1971), 66-75. 
[14] Bowles, S., Migration as Investment: Empirical Tests of the Human Investment Approach to Geographical Mobility, Review of Economics and Statistics, 52 (1970), $356-362$.

[15] Mincer, J., Labor-Force Participation and Unemployment: A Review of Recent Evidence, in Prosperity and Unemployment, R.A. Gordon and M.S. Gordon, eds., Wiley, New York, 1966.

[16] Phelps, E.S., ed., Microeconomic Foundations of Employment and Inflation Theory, W.W. Norton, Boston, Mass., 1970.

[17] Moseley, M.H., Growth Centers in Spatial Planning, Pergamon, Oxford, 1974 .

[18] Lansing, J.B. and E. Mueller, The Geographic Mobility of Labor, Survey Research Center, Institute for Social Research, University of Michigan, Ann Arbor, Mich., 1967.

[19] Morrison, P.A., Migration from Distressed Areas: Its Meaning for Regional Policy, R-1103-EDA/FF/NIH, Rand Corporation, Santa Monica, Calif., 1973.

[20] Tinbergen, J., On the Theory of Economic Policy, NorthHolland, Amsterdam, 1963.

[21] Fox, L., J. Sengupta, and E. Thorbecke, The Theory of Quantitative Economic Policy, North-Holland, Amsterdam, 1972 .

[22] Keyfitz, N. and W. Flieger, Population: Facts and Methods of Demography, W.H. Freeman, San Francisco, Calif., 1971 .

[23] Berelson, B., ed., Population Policy in Developed Countries, McGraw-Hill, New York, 1974.

[24] Rogers, A., Introduction to Multiregional Mathematical Demography, Wiley, New York, 1975.

[25] Zelinsky, W., The Hypothesis of the Mobility Transition, Geographical Review, 46 (1971), 219-249.

[26] Meadows, D.H. et al., The Limits to Growth, Universe Books, New York, 1972 .

[27] Frejka, T., The Future of Population Growth: Alternative Paths to Equilibrium, Wiley, New York, 1973.

[28] US Commission on Population Growth and the American Future, Population and the American Future, US Government Printing Office, Washington, D.C., 1972. 
[29] Morrison, P.A., The Impact of Population Stabilization on Migration and Redistribution, in Population, Distribution, and Policy, S.M. Mazie, ed., US Commission on Population Growth and the American Future, US Government Printing Office, Washington, D.C., 1972.

[30] Keyfitz, N., On the Momentum of Population Growth, Demography, 8 (1971), 71-80.

[31] US Bureau of the Census, Illustrative Population Projections for the United States: The Demographic Effect of Alternative Paths to Zero Growth, Census Populati Reports, Series P-25, No. 480, US Government Printin Office, Washington, D.C., 1972.

[32] Ryder, N.B., Notes on Stationary Populations, Population Index, 40 (1974), 3-28.

[33] Power, J., Sense of Helplessness, in International HeraZd Tribune (April 6, 1976), 4.

[34] Rogers, A. and F. Willekens, Spatial Zero Population Grow RM-76-25, International Institute of Applied Systems Analysis, Laxenburg, Austria, 1976. 
ion

wth, 